June 2003 • NREL/CP-500-34318

\title{
Grid Impacts of Wind Power: A Summary of Recent Studies in the United States
}

\section{Preprint}

B. Parsons and M. Milligan

National Renewable Energy Laboratory

B. Zavadil and D. Brooks

Electrotek Concepts, Inc.

B. Kirby

Oak Ridge National Laboratory

K. Dragoon

Pacificorp

J. Caldwell

American Wind Energy Association

To be presented at the 2003 European Wind Energy Conference and Exhibition

Madrid, Spain

June 16-19, 2003

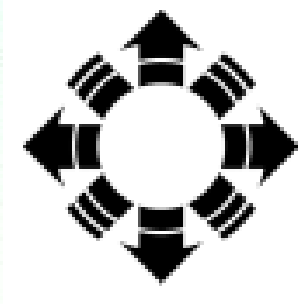

\section{NPEI}

National Renewable Energy Laboratory

1617 Cole Boulevard

Golden, Colorado 80401-3393

NREL is a U.S. Department of Energy Laboratory

Operated by Midwest Research Institute $\bullet$ Battelle $\bullet$ Bechtel

Contract No. DE-AC36-99-G010337 


\section{NOTICE}

The submitted manuscript has been offered by an employee of the Midwest Research Institute (MRI), a contractor of the US Government under Contract No. DE-AC36-99G010337. Accordingly, the US Government and MRI retain a nonexclusive royalty-free license to publish or reproduce the published form of this contribution, or allow others to do so, for US Government purposes.

This report was prepared as an account of work sponsored by an agency of the United States government. Neither the United States government nor any agency thereof, nor any of their employees, makes any warranty, express or implied, or assumes any legal liability or responsibility for the accuracy, completeness, or usefulness of any information, apparatus, product, or process disclosed, or represents that its use would not infringe privately owned rights. Reference herein to any specific commercial product, process, or service by trade name, trademark, manufacturer, or otherwise does not necessarily constitute or imply its endorsement, recommendation, or favoring by the United States government or any agency thereof. The views and opinions of authors expressed herein do not necessarily state or reflect those of the United States government or any agency thereof.

Available electronically at http://www.osti.gov/bridge

Available for a processing fee to U.S. Department of Energy and its contractors, in paper, from:

U.S. Department of Energy

Office of Scientific and Technical Information

P.O. Box 62

Oak Ridge, TN 37831-0062

phone: 865.576.8401

fax: 865.576.5728

email: reports@adonis.osti.gov

Available for sale to the public, in paper, from:

U.S. Department of Commerce

National Technical Information Service

5285 Port Royal Road

Springfield, VA 22161

phone: 800.553 .6847

fax: 703.605.6900

email: orders@ntis.fedworld.gov

online ordering: http://www.ntis.gov/ordering.htm

Printed on paper containing at least $50 \%$ wastepaper, including $20 \%$ postconsumer waste 


\title{
Grid Impacts of Wind Power: A Summary of Recent Studies in the United States
}

\author{
Brian Parsons and Michael Milligan, Consultant \\ National Wind Technology Center \\ National Renewable Energy Laboratory \\ 1617 Cole Blvd. \\ Golden, CO 80401 \\ USA \\ Brian Parsons@,nrel.gov \\ $+1-303-384-6958$ \\ Fax +1-303-384-6901 \\ Bob Zavadil and Daniel Brooks \\ Electrotek Concepts, Inc. \\ 408 N. Cedar Bluff Rd., Suite 500 \\ Knoxville, TN 37923 \\ USA \\ bob@electrotek.com \\ Brendan Kirby \\ Oak Ridge National Laboratory \\ P.O. Box 2008, MS6070 \\ Oak Ridge, TN 37831 \\ USA
bjk@,ORNL.GOV
$+1-865-576-1768$ \\ Ken Dragoon \\ PacifiCorp \\ 825 NE Multnomah St., Suite 600 \\ Portland, OR 97232 \\ USA \\ 503-813-5326 \\ ken.dragoon@pacificorp.com \\ Jim Caldwell \\ American Wind Energy Association \\ 122 C Street NW, Suite 380 \\ Washington, DC 20001 \\ USA \\ jcaldwell@awea.org
}




\section{ABSTRACT}

Several detailed technical investigations of grid ancillary service impacts of wind power plants in the United States have recently been performed. These studies were applied to Xcel Energy (in Minnesota) and PacifiCorp and the Bonneville Power Administration (both in the northwestern United States). Although the approaches vary, three utility time frames appear to be most at issue: regulation, load following, and unit commitment. This paper describes and compares the analytic frameworks from recent analysis and discusses the implications and cost estimates of wind integration. The findings of these studies indicate that relatively large-scale wind generation will have an impact on power system operation and costs, but these impacts and costs are relatively low at penetration rates that are expected over the next several years.

\section{PREFACE}

With the continuing decline in the busbar cost of wind energy and continuing spread of favorable renewable policies at the state and federal level, many U.S. utilities are taking a serious look at wind power. Foremost in these examinations are concerns associated with accommodating the variable nature of power production in the interconnected grid system. At first blush, the uncontrollability of output presents a formidable obstacle, often resulting in high estimates of ancillary service costs or assumptions that wind capacity must be "backed up" with large amounts of dispatchable conventional technology, such as natural-gas-fired combustion turbines. However, these cursory examinations often overlook key factors such as:

- The stochastic nature of grid systems, which must routinely contend with varying and uncertain demand, and unexpected transmission and generation outages

- The ability to forecast wind power output in both hourly and day-ahead time frames

- Actual wind farm power output characteristics, including multiple-generator smoothing (intra- and intersite) and new generator and wind farm interface abilities

- Large-scale geographic diversity resulting in smoothing of aggregate power output

- The evolution of U.S. competitive wholesale markets, including near-real-time operations and unscheduled deviation practices.

Recently, several more detailed technical investigations of grid ancillary service impacts have been performed. This paper will summarize the issues of grid integration, approaches and results of recent studies, and implications for future work.

Recent studies relevant to costs of grid integration of wind energy have been performed for the following utilities: Xcel Energy (in Minnesota) and Pacificorp and the Bonneville Power Administration (both in the northwestern United States). In addition, market rules from the Mid-Atlantic region (Pennsylvania, New Jersey, and Maryland, or PJM, power pool) have been examined for cost impacts. Although the approaches vary, three utility time frames appear to be most at issue: regulation, load following, and unit commitment. Market-based and integrated-provider, cost-based approaches to evaluation have been examined. The analytic frameworks will be described and compared, and implications will be discussed.

Grid integration costs imposed on the system are of foremost concern to utilities and grid operators. The analysis techniques and their application are in the early stages of development. These early studies provide the foundation for continuing analysis and give early indications of the magnitude of costs. Continued work is needed to identify the key grid characteristics that determine cost and to define the relation between increased amounts of wind on the system and associated increasing integration costs. Accurately assessing these costs is crucial to the development of wind resources in the United States, where investor-owned utilities must show that their resource decisions are prudent, lowest-cost alternatives to their regulatory agencies in regions where markets have not restructured.

The Xcel study, performed for the Utility Wind Interest Group (UWIG) by Electrotek, Inc., concluded that additional grid costs for integrating nearly $300 \mathrm{MW}$ of additional wind imposed system costs of around 0.18 cents $/ \mathrm{kWh}$ of wind energy produced (system peak for Xcel is about $7000 \mathrm{MW}$ ). PacifiCorp estimated additional costs of 0.5-0.6 cents $/ \mathrm{kWh}$ for integration of $2000 \mathrm{MW}$, nearly $20 \%$ of its system capacity. The Bonneville study, performed by Eric Hirst, found negligible integration costs for large amounts of wind, primarily because of the limited correlation between load forecast errors and wind forecast errors. Although the methods and level of detail varied in these studies, they 
provide an early indication that ancillary service costs imposed by wind are relatively low for the growth in wind power expected in the next 3-5 years. Experience gained during that time frame may reveal continued opportunity to integrate wind without large cost impacts as wind penetration increases.

\section{INTRODUCTION}

As the use of wind power increases around the world, there is increasing interest in the impacts on power system operation and costs. Because wind is an intermittent resource, the development of forecasting tools can be valuable to schedulers and dispatchers. Although forecasting tools are becoming more accurate, integrating large-scale wind power plants into the grid can still pose challenges.

Power system operation covers several time scales, ranging from minutes to days (Figure 1). Generators respond to changing load conditions in different ways, depending on the time scale and on operational practices. During minuteto-minute load fluctuations, an automatic generation control (AGC) computer often sends signals to one or more generators to cause an increase or decrease in output to match the changing load conditions. The service provided by this process is called regulation, and it occurs at a time scale ranging from approximately several seconds to 10 minutes. These movements in loads and generation are not typically predicted or scheduled in advance. To meet these fast fluctuations, sufficient generation must be online and synchronized so that there is enough flexibility to respond.

The next time scale is load following, which covers approximately 10 minutes to several hours. In this time scale, economic dispatch decisions are made in response to the trend in demand. During the early morning period, for example, an increase in load usually occurs from approximately 7:00 AM to mid-day or early afternoon. After the daily peak is reached, the load typically falls over the next several hours, finally reaching a daily minimum late at night. The utility or independent system operator is responsible for ensuring that sufficient capacity is available to meet these large, relatively slow swings in demand.

Some generators require several hours to be started and synchronized to the grid. That means that the generation available during the mid-day peak must have been started hours in advance, in anticipation of the peak. In many cases, the shut-down process is also lengthy, and units may require several hours of cooling prior to restarting. The decision to utilize this type of unit often involves a period of several days that the unit must run prior to shutting down in order to be economic. This time scale is called unit commitment, and it can range from several hours to several days, depending on specific generator characteristics and operational practice.

If significant new wind generation is added to the power supply, the impacts can extend to each of these time scales. Fast movements in wind output are combined with fast movements in loads and other resources in the regulation time scale. Scheduling conventional units to follow load is also affected by wind power output. During the morning load pickup during which more resources must be dispatched, if wind generation is also increasing and can be forecast reliably, then the system operator would need fewer load following resources. Conversely, wind output could drop during the morning load pickup.

If a wind plant's output could be perfectly forecast for several days in advance, it would help schedulers determine which units would need to be committed. In the absence of a perfect forecast, the unit-commitment decision must be made under uncertainty. The result is that sometimes a unit might be committed when it is not needed, and sometimes a unit might not be committed when it is needed.

There is a cost impact for each of these time scales. The focus of most of the studies described in this paper is to address these costs after calculating the changes in physical requirements for regulation, load following, or unit commitment. We attempt to measure these costs incurred by a utility or other similar entity that result directly from including wind power in the electrical supply. System integration service providers may charge a price that exceeds this cost in various wholesale markets, which we do not consider here. Of all the studies described here, the UWIG operational study was the most ambitious and addressed each of these time scales. Other work has focused primarily on load following or regulation impacts.

When comparing different wind integration studies, it is important to adopt a clear definition of the time scales involved. This can be complicated by differences in operational practice among different system operators. In this paper, we have endeavored to ensure that comparisons are consistent across our discussion of different studies. Regulation impacts are defined to be those impacts that occur on a minute-to-minute basis, are not scheduled, and are responded to primarily by AGC. Load following can occur at time scales as short as 10 minutes but will normally be 1 hour or more, and it is dependent on the dispatch stack that resulted from the unit-commitment process. 


\section{METHODS AND DEFINITIONS}

This section begins with a discussion of traditional electric production simulation models and some of the difficulties these models present when analyzing wind generators.

Commercial operational models are sometimes used to estimate the operational impacts and costs of wind integration. These models can provide valuable information about some of the impacts of wind but are limited in their capacity to provide detailed answers. In some cases, the modeling framework might provide a relatively accurate assessment of wind's impacts, but the assumptions and logic embedded in the model may not be transparent. That makes it difficult, if not impossible, to determine whether the modeling results have taken important aspects of wind into account. Although model shortcomings are covered in more detail in [1], this section summarizes some of the key issues.

Most operational models run in time increments that vary from several minutes to several hours, and they are run for a simulation period of days to weeks or more. The period of study encompasses unit commitment, load following, and regulation, although some models have difficulty with the regulation time scale. To economically operate a power system, many interconnected decisions must be made to ensure sufficient generation to meet loads plus a reserve margin, without scheduling more capacity than is needed. Wind complicates the unit-commitment decision because of the difficulty in accurately forecasting wind output over the unit-commitment time frame. Most commercially available models use exogenous inputs from the user to determine the level of wind output that can be counted toward the unitcommitment decision. Further, the specific algorithm used by these models is highly complex and proprietary. That makes it difficult to untangle the causal chain of events when wind is added to the power supply.

Models also do not generally account for the uncertainty of wind generation in the load following time scale. Errors in unit commitment are propagated in the economic dispatch/load following time scale. This can cause an inefficient dispatch to occur because of unit-commitment errors.

\section{EMERGING METHODS FOR ANALYZING GRID IMPACT OF WIND}

Because of these and other shortcomings, many techniques have recently evolved that allow the analyst to focus more precisely on specific time scales. Although these methods may not be as robust as more complete modeling frameworks, they offer the advantages of clarity and focus on specific ancillary services. These approaches typically begin with an underlying physical analysis, followed by applying appropriate costs or prices to estimate the economic impact.

Electric power is unique in that aggregate production and consumption must be balanced essentially instantaneously and continuously; there is little practical storage. Fluctuations in the power being consumed by loads and uncontrolled generators must be matched by fluctuations of controlled generators. Fortunately it is not necessary to compensate for each individual's fluctuations individually. Only the aggregate control area load and generation need to be balanced. Control area balance does not have to be perfect either. The North American Electric Reliability Council (NERC) has established statistical standards (Control Performance Standards 1 and 2) for how well each control area must balance aggregate generation and load. The NERC standards are discussed in a later section of this paper.

Balancing the power system occurs over several time frames. Years in advance, for example, enough generation has to be planned and built so that there is sufficient capacity available to meet load requirements. Closer to real time, system operators forecast day-ahead load requirements and select which available generators can reliably meet the expected requirements at the lowest cost. Obtaining accurate forecasts from individual loads and generators is important, but only because collectively they constitute the aggregate forecast within a control area. If one individual forecast is low and another is high, the errors tend to cancel. Uncorrelated errors do not add linearly.

Forecasting errors result in costs either because the system operator knows the forecast is unreliable and includes additional reserves in the mix of committed generation or because unforeseen errors result in the need to adjust the generation mix at the last minute. In either case, the resulting generation mix will be sub-optimal.

In real time, available generation must be dispatched to match the actual power fluctuations of aggregate load and uncontrolled generation. These fluctuations can be split into load following and regulation. Figure 2 shows the aggregate system load for a typical utility for 1 day. There is a clearly discernable daily pattern of low load at night, rising consumption during the morning, and falling consumption during the evening. Superimposed on this daily cycle are faster random fluctuations. Load following and regulation can be separated, as shown in Figure 3. This is useful because the faster, random, regulation fluctuations must be compensated for with dedicated generation capacity that is on AGC. Regulation is a capacity service and does not involve any net energy. A given level of capacity that is supplied over some time period is denoted as MW-hr, as contrasted with the similar measure of energy, MWh. The 
slower load following ramps can be met by adjusting generation schedules and the imbalance energy market. Table 1 shows the significant distinguishing features of load following and regulation.

Both regulation and load following must be dealt with on a control area basis. Each individual's variations do not have to be compensated for directly, but the aggregation must be balanced. The fast, random fluctuations associated with regulation are typically uncorrelated. Consequently, the total regulation requirement is not the sum of the regulation requirements of the individual loads and uncontrolled generators but is instead the sum of the correlated components. Load following requirements tend to be more highly correlated-most loads rise in the morning. Still, because load following requirements are not perfectly correlated, the total system load following requirement is less than the sum of the load following requirements of the individuals. This aggregation of loads has a powerful effect on system planning and operation because the system must respond to total variations, not the sum of individual variations.

When wind power plants are introduced into the power system, an additional source of variation is added to the already variable nature of the system. To analyze the additional variation caused by wind generators, every change in wind output does not need to be matched one-for-one by a change in another generating unit moving in the opposite direction. This is a direct consequence of the requirement that the entire system must be balanced instead of balancing each individual load or resource.

Once the total system variability is calculated, we can calculate the contribution of individual loads or resources to the total. This type of analysis can be done in the regulation time scale or load following time scale. Minute-to-minute fluctuations in individual loads are largely uncorrelated, providing a tremendous aggregation benefit. Likewise, minuteto-minute fluctuations in wind output are largely uncorrelated with load. This implies that the additional variation that wind plants add to the system do not add linearly.

One way to calculate the regulation cost imposed by a wind plant is to estimate the incremental regulation that is required. The standard deviation of the load can be calculated and then compared to the standard deviation of the combined load and wind signal. If the combined standard deviation were $5 \%$ greater than for load alone, then the method would allocate an additional $5 \%$ in regulation cost to the wind plant.

However, this method does not recognize the possibility of positive or negative correlations between load and wind, is not independent of the order in which loads or resources are added to the system, and breaks down when repeatedly applied to a large number of loads or resources. If a wind plant is highly correlated with load, then it might impose a significantly larger regulation requirement and should pay a higher regulation cost. Conversely, if the wind output were negatively correlated with load, it could conceivably reduce the system-wide regulation requirement.

Kirby and Hirst [2] developed a method that is not subject to these difficulties and can handle any level of correlation and any number of individual loads and/or resources. We refer to this as the Oak Ridge National Lab (ORNL) allocation method. The share of an individual load or resource is calculated by

$$
\sigma_{i \text { allocation }}=\frac{\left(\sigma_{\text {Total }}^{2}+\sigma_{i}^{2}-\sigma_{\text {Total }-i}^{2}\right)}{2 * \sigma_{\text {Total }}}
$$

Where each of the $\sigma$ 's represents a standard deviation, the subscript $i$ is the individual of interest (for example, a wind plant), and $\sigma_{\text {Total-i }}$ represents the standard deviation of the system excluding individual $i$.

Figure 4 illustrates a hypothetical system with and without two highly variable loads. We can see from the graph that the total variation is less than the sum of each individual variation. If we were to allocate the overall variability to loads 1 and 2, we could use the method represented by Equation (1). Later sections of this paper will discuss studies that have used these methods of allocation to wind power plants. 


\section{DEFINITIONS}

Power systems do not maintain a constant state of balance between loads and resources. However, the extent of imbalance must be controlled. NERC specifies a performance criterion to assess the statistical nature of this imbalance. This area control error (ACE) is

$$
A C E=\left(N I_{A}-N I_{S}\right)-10 \beta\left(F_{A}-F_{S}\right)-I_{M E}
$$

$N I_{A}$ is the sum of all flows on all lines within the boundary of the control area, and $N I_{S}$ is the sum of all scheduled tie flows within the control area. $\beta$ is the frequency bias setting $(\mathrm{MW} / 0.1 \mathrm{~Hz}$; the multiplication by 10 converts to $\mathrm{MW} / \mathrm{Hz}$ ), the $F$ terms represent actual and scheduled frequency, and $I_{M E}$ is the metering error. Prior to the development of some statistical measures discussed below, ACE was required to cross 0 at least once every 10 minutes.

In 2002, NERC set statistical standards [3] for allowable deviations from zero ACE. These are control performance standards 1 and 2 (CPS1 and CPS2). CPS1 measures the relationship between the control area ACE and the interconnection frequency on a 1-minute basis. CPS2 is based on a monthly standard and sets limits on the maximum average ACE for each 10-minute period. Further details can be found in the NERC report.

The NERC performance standards have an important implication for the analysis of wind system integration. These standards are based on overall system performance, not on individual generator performance. As discussed below, the emerging methods for wind integration analysis recognize this important feature of control area operation and performance.

Finally, dynamic scheduling is discussed in some of the studies below. The Federal Energy Regulatory Commission (FERC) in its Order 888 defines dynamic scheduling, which is the electronic transfer of the time-varying electricity consumption associated with a load or the time-varying electricity production associated with a generator from one control area to another. Dynamic scheduling is accomplished by metering the real-time consumption (or generation) of the load (or generator) that is to be transferred, subtracting that load (or generation) from the ACE equation of the control area where the load (or generator) physically resides, and adding that load (or generation) to the ACE equation of the control area that it is being dynamically scheduled to. Dynamic scheduling moves the control requirements associated with one (or more) physical entity or entities from one control area to another. Further details can be found in [4].

\section{ANALYTIC STUDIES}

Some recent analyses of wind energy and operational impacts have illustrated methods and techniques for calculating these impacts using hypothetical examples based on real data. Here we review two such studies. The first was done by Eric Hirst [5] and applied real wind generation data from the Lake Benton II wind farm to actual load data from the PJM interconnection in the United States. The PJM interconnection also includes all or parts of Virginia, West Virginia, Ohio, Delaware, and the District of Columbia. The second study used load and wind data from Iowa to examine the load following requirements impact of wind power plants at different penetration rates.

\section{LAKE BENTON II/PJM STUDY}

Eric Hirst performed a study [5] to help determine how wind generators might interact in competitive wholesale markets for regulation services, an hour-ahead energy market, and a real-time intra-hour balancing market. The study used data collected by the National Renewable Energy Laboratory (NREL) from the Lake Benton II (LB) wind farm in Minnesota [6]. Because the PJM interconnection has several features that may become a part of some new wholesale power markets, some of the characteristics and prices from PJM were used in this study to capture the influence of real markets. Data from LB were used for the study because there are limited wind farm data in existence that could be used for such a study.

One of the most influential aspects of Hirst's study was the focus on system balance, rather than on individual resource balance. The Hirst study recognizes that the NERC performance requirements apply to the system, not to each individual generator. Wind integration does not require that each movement in wind output be matched by a corresponding and opposite movement in another resource. Because the power system already encompasses enormous variation in customer loads, adding a variable resource, such as wind, simply adds to the existing system variation. 
The study begins by calculating the physical impacts of wind on the grid for two 1-week periods, in January 2001 and August 2000, respectively. The wind generation was assumed to be dynamically scheduled in the PJM system. Using a simple statistical wind forecast method, the impact of wind on hourly system imbalance was estimated. The actual PJM hourly prices from the relevant time period were used to calculate the revenue that a wind operator could earn if the wind output were scheduled as forecast. Any deviations from the forecast were treated as imbalances, and a penalty payment was assessed on the wind plant using PJM imbalance prices.

To estimate the impact on regulation, a 30-minute rolling average was applied to the 1-minute data to split the hourly imbalance from the regulation requirement. To allocate the regulation impact to the wind plant, the Oak Ridge National Laboratory (ORNL) allocation method was applied to the data. Then the PJM regulation price was applied to wind's allocation.

The results are split according to whether the wind plant utilizes the hour-ahead (HA) market, bidding the forecasted level of wind power and paying an imbalance penalty for forecast deviations, or whether the wind generation appears only in the imbalance market. Table 2 illustrates the results for a wind plant that participates in the HA market.

The table shows the average generation from each of the study periods, along with the prices received (or paid) by the wind operator. In August, the average price received by the wind plant is $\$ 34.70 / \mathrm{MWh}$. Because of the forecast inaccuracy, the wind operator is assessed an imbalance price of $\$ 2.80 / \mathrm{MWh}$ and also must pay $\$ 0.30 / \mathrm{MWh}$ in regulation cost. During the January study period, the wind generation was significantly higher than in August, but the average price received by the wind plant is less than in August. Regulation costs were also lower, in part because of the lower overall regulation cost during January and in part because wind's allocated share was less in January.

Table 3 shows the price received by the wind plant operator assuming that all the wind energy appears in the imbalance market. The results of this study are clearly limited to the time periods, prices, and other assumptions, and care must be used in extrapolating these results to other markets. However, this study does help establish plausible order-ofmagnitude estimates of the imbalance and regulation costs of a wind plant. More important, this study is one of the first to recognize the importance of overall system balance and to use actual data to calculate the integration costs of a wind power plant.

\section{IOWA LOAD FOLLOWING AND IMBALANCE STUDY}

Milligan [7] developed a case study using 1 year of actual wind speed data and hourly load data for Iowa. These data were utilized in a prior study that helped determine the optimal sizes and locations of power plants in Iowa [8].

The goal of this analysis was to determine the change in load following requirements that are induced by alternative wind plant configurations that represent different penetration rates of wind relative to annual system peak load. No attempt was made to determine which of the conventional generating units would compensate for the variable output of wind, nor are any cost estimates developed for the load following impact of wind. Instead, this analysis focuses on the physical requirements that wind would impose on the electrical supply.

The first part of this study examined the post hoc load following requirements, ignoring the influence of either load forecast errors or wind forecast errors. Several different wind configuration scenarios were examined, with differing levels of capacity placed at different locations in the state. The maximum wind capacity analyzed is 1,600 MW, and other, lower penetration rates were also examined.

Because utilities already operate the system to match changes in hourly load requirements, this analysis begins by calculating the hour-to-hour ramping requirements, assuming no wind generation is installed on the system. Once this baseline is established, wind generation is added at different penetration rates and at different locations. To calculate the fair-share allocation of the load following requirement on the wind plants, the ORNL vector allocation method was applied to each case.

At each penetration rate, eight scenarios were examined. Each of these scenarios represents a different way of spreading the wind development among the six sites. One of the eight cases had most of the wind capacity at a single site, and the remaining seven cases had significant geographic dispersion.

Figure 5 summarizes these results. The line labeled "Case 1" represents a very limited geographical dispersion of the wind generators. The remaining seven cases were combined, and the largest impact was selected from each case at each wind capacity level that appears in the graph. 
The second part of this study examined the impact of wind plants on hourly system imbalance. For systems without wind plants, the primary source of imbalance is the deviation of actual load from predicted load. Some conventional generators can also contribute to imbalance if they do not respond quickly enough to operator commands. When wind power is a part of the power supply, additional imbalance is created when the actual wind output deviates from its forecast. Errors in load forecasts are generally uncorrelated with errors in wind forecasts. That has a powerful implication for the combined forecast errors: In some hours, both the wind forecast and load forecast may be too high or too low, or they may offset each other. Any attempt to examine the imbalance impact of wind must take this into account.

The Iowa study adapted load forecast errors from the California Independent System Operator (CAISO) to the Iowa load data and used a simple persistence forecast for the wind plants. To estimate the effect of increasing wind forecast accuracy, the wind forecast errors were also reduced to provide a range of wind forecast errors. Figure 6 illustrates some of the key results from the study.

Each line in the graph shows wind's fair share allocation of imbalance, calculated with the ORNL allocation method. The top curve shows this imbalance at different penetration rates of geographically disperse wind. The relationship between the curves is nonlinear, which implies that larger quantities of wind will have a larger impact on imbalance. The other two curves are based on $20 \%$ and $40 \%$ improvements to wind forecasting, respectively. If a utility were to set aside enough reserves to cover 3 standard deviations of hourly imbalances, wind's share would be approximately $3 \mathrm{x}$ $68=204 \mathrm{MW}$ in the persistence case, with $1600 \mathrm{MW}$ of installed wind. This represents just under $13 \%$ of the installed capacity of the wind plant.

\section{UTILITY CASE STUDIES}

\section{UWIG STUDY OF XCEL ENERGY AND LAKE BENTON II}

UWIG commissioned a research project to quantitatively evaluate the impact of wind generation on system operating costs for one of its members, Xcel Energy-North, formerly Northern States Power Co. (NSP). Further details on this study can be found in [9]. The final report should be posted on the UWIG Web site (http://www.uwig.org/) by the end of June 2003. The primary objectives of the study were to:

- Identify and quantify incremental operating costs on real-time control area operations attributable to existing wind generation facilities

- Determine how uncertain wind generation forecast information affects operating costs associated with short-term scheduling and commitment of conventional generating units.

The case study was structured to evaluate the notions of the control area operators that accommodating large wind generation facilities was increasing operating costs. Consequently, the scenarios for the study were defined to closely match the existing operational practices and procedures. While of importance going forward, changes to existing procedures that might minimize integration costs were outside the defined scope of the initial research project.

\section{Case Study Background}

By calendar year 2000, Xcel Energy had a nameplate wind generation capacity of about $280 \mathrm{MW}$ in its northern control area. This area includes $75 \%$ of the power consumption of Minnesota and smaller parts of Michigan, Wisconsin, and North and South Dakota. Xcel's generating resources are predominantly thermal, with the total thermal generating capacities exceeding $7000 \mathrm{MW}$. Peaking units fueled by natural gas and oil comprise $20 \%$ of this capacity. The remaining $80 \%$ of Xcel's thermal capacity is obtained from more economical units fueled by coal, nuclear energy, and wood.

Xcel's load demand is highest in summer (8000 MW), moderate in winter (6000 MW), and lowest during spring and fall $(5000 \mathrm{MW})$. Because control area load exceeds the capacity of its most economical generation, Xcel keeps these economic units online virtually all the time, except when they are on maintenance or forced outage. Xcel purchases energy to make up for its shortage of economic generation to meet its load. During the high-load summer season, the hourly import is as high as $2600 \mathrm{MW}$ with a net energy import of about $16 \%$ of the total load MWh. Xcel also imports energy in other seasons, but the magnitude of the imports is less for these seasons. As part of the Mid-Continent Area Power Pool, Xcel's reserve share is $161 \mathrm{MW}$ of spinning reserve and $160 \mathrm{MW}$ of non-spinning reserve. Xcel also belongs to the Midwest Independent Transmission System Operator (MISO), in operation since February 2002 to provide transmission-scheduling services. Nonetheless, at the time of the study, Xcel operated in a regulated, vertically integrated environment, and that structure formed the basis for the analytical approach taken in the case study. 


\section{Methodology}

Traditional utility scheduling and operation tools were used for the quantitative evaluation. These tools allow for timeseries simulations of the relevant scheduling and control functions. Due to the variable and somewhat random nature of wind, the results of any single time-series simulation may not accurately represent the impacts of wind on the scheduling and control functions. Consequently, a Monte Carlo approach was utilized, whereby many realizations of wind generation time series are used in the simulations to provide a distribution of results that are statistically representative of the impacts of the Xcel wind regime and not a single realization of the wind. A probabilistic wind plant model and tool were developed using 1-second high-resolution wind data supplied by NREL and using 5-minute and hourly resolution wind generation data supplied by Xcel. The developed wind models were used to synthesize multiple wind generation time series for each scenario evaluated for each of the simulation time scales. As is often the case, however, utility system data was more limited at the higher resolution time scales. Nonetheless, the impacts of each wind generation time series were evaluated in a deterministic manner with the available system data. The distribution of the impact values were compiled and used to provide a more representative assessment.

A graphical overview of the analytical methodology used for the case study is found in Figure 7.

\section{Results}

The following cost impacts were assessed using the simulation framework and appropriately selected system operating scenarios:

- $\quad$ Cost of wind generation forecast inaccuracy for day-ahead scheduling

- Cost of additional load following reserves

- Cost of intra-hour load following "energy component"

- Cost of additional regulation reserves.

Cost of wind generation forecast inaccuracy for day-ahead scheduling. Unit-commitment simulations were performed to assess the cost incurred by Xcel to reschedule units because of unavoidable inaccuracy associated with the wind generation forecasts used in the day-ahead scheduling. Several assumptions were utilized in the problem formulation, partly to simplify the evaluation model and partly to account for unavailable data. The methodology utilized provided a cost impact based on the assumed distribution range of forecast error. The results of the study also enabled the derivation of a specific operational planning strategy, similar to a loosely defined procedure already used by Xcel, to hedge against the adverse effect of wind generation forecast uncertainty. As demonstrated in the results, the cost impacts decrease as the forecast accuracy increases; in the study, they ranged from $\$ 0.39 / \mathrm{MWh}$ to $\$ 1.44 / \mathrm{MWh}$ of wind generation for day-ahead forecast errors of $10 \%$ to $50 \%$.

Cost of additional load following reserves. Calculation of the load following reserve requirement (LFRR) of the Xcel hourly resolution control area load and aggregate wind generation data for January and July of 2000 indicated that the addition of wind does not significantly increase the LFRR. Consequently, the reserve component of the load following cost is assumed to be zero without performing the unit-commitment simulations that would be required to obtain a specific cost impact value. It should be noted that this determination is for the existing Xcel wind penetration level. Assuming a reserve component cost of zero for wind means that the energy component assessed using intra-hour economic dispatch simulation will be higher than the energy component cost that would be calculated if additional load following reserves were added to support the wind.

Cost of intra-hour load following "energy component." Economic dispatch simulations were performed to evaluate the cost of following the intra-hour ramping and fluctuation of wind generation. This cost is referred to as the intra-hour load following "energy component" because it is the cost of deploying the available load following reserve to meet the intra-hour slow variation of load changes. Economic dispatch simulations were performed for 4 hours of the day selected to represent the different load ramping and wind variation characteristics associated with Xcel's typical daily load curve. The average cost for a day was extrapolated from the simulations for these 4 hours by dividing a day into 4 different periods based on the load ramping characteristic with each period including a simulated hour. Additional assumptions and extrapolations were made to obtain an annualized intra-hour load following "energy component" cost of approximately $\$ 0.41 / \mathrm{MWh}$.

Cost of additional regulation reserves. Load frequency control (LFC) simulations were performed for 4 representative hours of the day to calculate the impact of minute-by-minute system load and wind generation fluctuation on Xcel's ACE statistics. Simulations were performed for no wind generation versus Xcel's current wind generation penetration level without extra regulating reserve. Results show almost no change in the ACE standard deviation between the without- and with-wind-generation scenarios. This suggests that Xcel's current wind penetration 
of $280 \mathrm{MW}$ on an 8000-MW peak system has no impact on the control performance. This means that for Xcel's current wind penetration level and regulating capacity and for the reserves allocated in the simulations, the variability of the wind on the 4-second time frame didn't significantly affect the capability of the system to follow these variations. Accordingly, the cost impact of additional regulating reserves to accommodate wind is assumed negligible. It should be noted that the regulating burden does increase, however, by approximately $4 \%$. The existing system is able to absorb this increase such that the increase does not impact the performance criteria.

\section{Summary}

The analytical approach utilized for the case study was based on conventional utility tools for chronological simulation of power system operation. From these simulations, incremental costs attributable to accommodation of wind generation can be quantified. Results are potentially sensitive to a wide range of factors, including wind penetration level, generation mix, and energy transaction pricing. The cost impacts are summarized in Table 4.

Several assumptions were made in modeling host utility system operations, many of which the investigators believe provide a conservative estimate of the cost impacts. Perhaps the most notable of these conservative assumptions was the assumption of perfect load forecasting, such that no diversity was achieved in modeling the wind forecasting uncertainty. Evaluation of the impacts of the wind uncertainty in isolation yields a "worst-case" analysis of the forecast uncertainty impact cost component. It should also be noted that the forecast uncertainty results obtained are strongly correlated to the vertically integrated operations environment modeled for the case study utility.

\section{PACIFICORP IRP}

PacifiCorp is a large utility in the northwest region of the United States. It serves loads in six states and two control areas. Figure 8 depicts a map of the service territory. PacifiCorp recently filed an integrated resource plan (IRP) to determine the likely course of action to increase its electrical supply to meet future demand.

The utility purchases $83 \mathrm{MW}$ of wind energy that is located in Wyoming and provides integration services for more than $200 \mathrm{MW}$ of wind generation in Wyoming and along the eastern Oregon-Washington border. A number of different scenarios were analyzed in the IRP, including several resource mixes that included significant additional wind resources. The least-cost plan resulted in $1400 \mathrm{MW}$ of wind capacity that was found to be part of the lowest cost resource portfolio [10].

To analyze the wind integration costs of wind, PacifiCorp divided the cost components into two categories: incremental reserve requirements and imbalance costs. The incremental reserve category accounted for the estimated cost of increasing the level of operating reserves necessary to maintain system reliability with a relatively large penetration of wind capacity. The imbalance cost category was intended to capture the difference in operating costs that may occur because of additional unit start-ups, a higher rate of incurring bid-ask spread penalties, or operating a unit at a less efficient point on the heat-rate or power curve.

To assess the incremental reserve requirement, the wind generation was treated as a negative load. This approach recognizes that each individual resource does not need to be balanced as long as the overall system is in balance. Because there is already significant hour-to-hour variability in system load, this approach recognizes that variability and looks at the incremental variability that is imposed by the wind plant. One year of hourly load and wind generation data were used in these calculations, and the approach is similar to the Iowa study discussed above. ${ }^{1}$ This analysis ignored the potential impact of regulating reserves, partly because the impact was judged to be small, and partly because customers are not now charged based on their relative contribution to regulation requirements in the PacifiCorp system. The results of the reserve requirement calculation appear in Figure 9. The results are consistent with the Iowa study, as the reserve impact increases faster at higher penetration rates.

The imbalance costs were assessed by running Henwood's PROSYM hourly dispatch model and comparing the nowind case with various penetration cases of wind energy. The results are summarized in Figure 10. For this analysis, the wind generation was modeled as a flat block of constant output for each hour, with the annual energy matching the energy from the wind plant. The intent of these differential runs was to capture the difference in dispatch costs and unit start-ups that are imposed by the variability of the wind resource. This approach represents a first approximation of the cost of meeting load with wind compared to meeting load with a standard market product. The complex interactions between wind power and the remaining power system are not fully captured by models such as PROSYM. For example, wind generation is modeled as a must-run unit with no probabilistic component. Modeling in the PacifiCorp

\footnotetext{
${ }^{1}$ The Iowa study used the ORNL allocation method to calculate wind's impact on load following, whereas the PacifiCorp IRP assessed the incremental impact on wind.
} 
analysis also did not capture the potentially complex interaction between wind and hydro. Although the analysis in PacifiCorp's IRP can be improved on, it likely represents a reasonable approximation of the integration cost of wind. Further discussion and caveats to the analysis can be found in [1].

The average integration cost for $2000 \mathrm{MW}$ of wind was estimated by the PacifiCorp IRP to be approximately $\$ 5.50 / \mathrm{MWh}$. Of that, $\$ 3.00 / \mathrm{MWh}$ was attributable to imbalance cost and $\$ 2.50 / \mathrm{MWh}$ for incremental reserve costs.

\section{HIRST'S STUDY FOR BPA}

The Bonneville Power Administration (BPA) is a federal agency under the U.S. Department of Energy that operates the transmission system and markets electricity at cost from 31 federally owned dams, one nuclear plant, and a large wind energy program. About $45 \%$ of the electric power used in the Northwest comes from BPA. BPA's transmission system accounts for about three-quarters of the region's high-voltage grid and includes major transmission links with other regions (http://www.bpa.gov/). Figure 11 depicts a map of the BPA system.

The amount of wind capacity in the Pacific Northwest is growing rapidly. As of mid-2002, BPA had 198 MW of wind under contract and another $580 \mathrm{MW}$ under consideration and had received requests for interconnection of about 5000 MW of wind capacity in Oregon and Washington. BPA commissioned Eric Hirst to perform a preliminary analysis of the cost of integrating wind energy into the BPA system [11]. The study focuses on the time between day-ahead operational planning (e.g., production of a system load forecast and preparation of hourly schedules for generating-unit operation) and real-time operations (i.e., the minute-to-minute movements of certain generating units to maintain the necessary generation to load balance). Specifically, this study examined day-ahead forecasting errors for the BPA system load and wind output plus the real-time requirements for the regulation and load following (intrahour balancing) ancillary services.

Hirst identified three time frames in which to analyze integration cost impacts:

- $\quad$ Day-ahead (DA) unit-commitment decisions concerning which units to turn on and when to do so. The ability of a wind farm to bid into such DA markets will depend strongly on the accuracy of the wind forecast used by the wind farm manager.

- Intrahour balancing performed by participating in the intrahour energy market to maintain the necessary balance between generation and load. This is done by running an economic-dispatch model every 5 to 15 minutes to move generators up or down to follow changes in load and unscheduled generator outputs at the lowest possible operating cost. Generators that participate in the system operator's balancing market provide the load following ancillary service.

- Regulation tracks changes in the minute-to-minute balance between generation and load, the system operator uses its AGC system to dispatch those generators providing the regulation ancillary service. These generators respond to short-term generation-load imbalances that are not addressed by the economic-dispatch process.

BPA supplied 2-second data from four wind farms: Vansycle (25 MW), Stateline (90 MW), Condon (25 MW), and Klondike (24 MW), with a total capacity of $164 \mathrm{MW}$. BPA also supplied 15-minute data from Foote Creek 1 (15 MW). BPA also supplied 2-second, 5-minute, and 1-hour data for total control area load and reserve requirements.

Hirst deliberately made assumptions that were unfavorable to wind (when assumptions were required) in order to produce conservative results. "These conservative assumptions include (1) stylized wind forecasts ... which can surely be improved upon; (2) scaling to larger wind farms that ignores the diversity benefits of geographical dispersion; and (3) use of a high price $(\$ 5 / \mathrm{MW}-\mathrm{hr}$ ) for capacity required in real time that was not scheduled day ahead. As a consequence, wind farms are likely to require fewer BPA resources at a lower cost than estimated here." Additionally, the results are based on only 4 months of data. Hirst cautions that these initial results should be viewed cautiously and advocates additional study.

Given the above caveats, the study calculated the increased amount of reserves required in each of the three time frames to compensate for $1000 \mathrm{MW}$ of additional wind generation. 


\section{DAY-AHEAD FORECAST ERROR}

In evaluating the impact wind generation has on the day-ahead unit-commitment problem, the study notes that costs arise because of the errors in the aggregated forecast of load, wind generation, and other uncertainties. Load forecasts are good, with an average absolute error of only $3 \%$ or $167 \mathrm{MW}$, but range from -1080 to $+960 \mathrm{MW}$.

Forecasts of wind output were not available. The project did not include the development of a wind forecast, so two very simple proxies were used. One used the daily average wind plant output as the forecast for output each hour, and the other used the monthly average wind plant output. A forecast error was then calculated by subtracting the daily or monthly average output from the actual hourly output. The average absolute error for the 164 MW of wind capacity was found to be $24 \mathrm{MW}$ and $41 \mathrm{MW}$ respectively for the two forecasts. These errors are much higher, $46 \%$ and $79 \%$, than the $3 \%$ error for load. A key finding was that wind and load forecast errors were found to be highly uncorrelated, and combining the wind and load errors resulted in only a small increase in total forecast error. Total forecast error increased from $167 \mathrm{MW}$ for load alone to $168 \mathrm{MW}$ for load plus wind using the daily average as a forecast and 171 MW using the monthly average as the wind forecast.

Hirst calculated the forecast error from a hypothetical 1000-MW wind plant by linearly scaling up the actual plant output. As the report acknowledges, this ignores the reduced variability that inevitably results from the increased geographic diversity. To try to estimate the monetary cost of the forecast error, the report assumed a $\$ 5 / \mathrm{MW}$-hr charge for any increase in total forecast error. No credit was given when the wind plant reduced the forecast error, a situation that occurred about half the time. The report also notes that the $\$ 5 / \mathrm{MW}-\mathrm{hr}$ charge is rather high - more than double the price for reserves in well-developed markets. With these intentionally conservative assumptions, the report found that the forecasting error impact of the $164 \mathrm{MW}$ of wind plants is de minimus. The cost associated with forecasting errors for the $1000-\mathrm{MW}$ wind plant would be $\$ 1.0$ to $\$ 1.8 / \mathrm{MWh}$ of wind output for the two forecast methods studied.

\section{INTRA-HOUR LOAD FOLLOWING}

Hirst defines load following as the signed difference between the highest and lowest 5-minute average load during each hour. As with forecast errors, the impact on total system requirements (load plus wind) is important. The study found that load following requirements of wind and system load are uncorrelated. Adding a 1000-MW wind plant (conservatively linearly scaled up from the 164-MW actual facility) with an average 70-MW load following requirement increases the total system average hourly load following requirement from $280 \mathrm{MW}$ to $290 \mathrm{MW}$.

Using the same conservative $\$ 5 / \mathrm{MW}-\mathrm{hr}$ cost and giving wind no credit for reducing the total system load following requirements (this occurred during $52 \%$ of the hours), the calculated load following cost was $\$ 0.28 / \mathrm{MWH}$ of wind generation.

\section{REGULATION}

Generators on AGC compensate for the minute-to-minute fluctuations of the aggregate system (load plus wind). To calculate the impact of $1000 \mathrm{MW}$ of wind, Hirst scaled up the minute-to-minute variability of the $164 \mathrm{MW}$ of actual wind generation by the square root of the size of the wind plant, accounting for the diversity associated with larger wind facilities. Regulation requirements were allocated based upon the ORNL method developed by Kirby and Hirst [2]. BPA does not have a market for regulation. The average cost of $\$ 11 / \mathrm{MW}$-hr from the NY-ISO was used instead. This resulted in a regulation cost of $\$ 0.19 / \mathrm{MWh}$ of wind generation.

Table 5 presents the calculated costs for $1000 \mathrm{MW}$ of wind generation integrated into the BPA system. As mentioned above, assumptions are deliberately conservative. The costs are dominated by the forecasting error costs, for which very simple forecast models were used.

\section{CURRENT AND FUTURE STUDIES}

California recently enacted a renewable portfolio standard. This legislation requires the investor-owned utilities in the state to increase the renewable share of energy production by at least $1 \%$ per year, achieving $20 \%$ by 2017 . Bids from renewable energy companies will be adjusted to account for any integration cost. So that these costs could be quantified, the California Wind Energy Consortium, under contract to the California Energy Commission, has begun to study this issue. For wind energy generators, two impacts will be studied. The first is the regulation impact, and the estimated increase in system regulation cost will be added to the wind bids. The second impact is a capacity credit, which is the quantity of wind capacity that will be counted toward meeting the system adequacy requirements. The following Web site has been established for the integration study: http://cwec.ucdavis.edu/rpsintegration. 
A third potential cost impact, load following impact, is not part of the study. A tariff amendment for the CAISO, the grid manager in California, allows intermittent resources such as wind to participate in an ISO-managed forecasting program. The forecast itself must be unbiased so that shortfalls in actual wind output relative to the wind forecast are offset by under-forecast wind power over each month. For generators that participate in this program, an imbalance account is created, and forecast deviations are netted over the month. Because the forecast is required to be unbiased, the net deviations would be expected to be near zero; however, any monthly net deviations that remain are paid or charged for the imbalance at a weighted average market price. Further information can be found on the ISO Web site [12].

MISO is working on a study to examine some of the impacts of 10,000 MW of wind on the MISO system over the next few years. Although this is not an operational study per se, there is considerable interest in the profiles of the projected wind plants and the impact on other generation in the region [13].

Another similar study is underway to examine the impact of increased reliance on renewable generating technologies in the western region of the United States. Various scenarios resulted in 8500-9200 MW of new wind generation by 2020. Although there are some results from the study today, further work will quantify various risk elements, such as fuel price risk and adverse hydro conditions [14].

In Minnesota, new legislation was recently passed that may result in significant new wind generation in that state. An independent study of the integration cost of 825 MW of wind capacity on the Xcel system will be done by June 2004, and there might be additional wind capacity beyond the $825 \mathrm{MW}$ depending on the findings of the integration cost study.

As a result of Hirst's study on the BPA system, BPA has begun its own internal study of the integration impacts and costs of wind. This study is nearing completion, and utilizes a full year of data rather than the limited data that was available for the Hirst study.

Finally, the Western Area Power Administration (WAPA), the federal hydro marketing agency, is developing a tariff for wind power plants. This project is expected to result in a new rate for regulation impacts of wind that will go into effect January 1, 2004. Although it is still evolving, the method appears to treat wind in isolation from the system regulation requirements. Information on this project will appear on WAPA's Web site (http://www.wapa.gov/).

\section{CONCLUSIONS}

Although the final word on wind integration cost has not yet been heard, the results of these U.S. studies can be used as a first approximation. Of course, any study that involves the complex interactions of wind power with conventional power system operation requires a number of simplifying assumptions. When commercial electricity production simulation models are applied to problems such as these, we believe that a reasonable estimate of wind integration costs can be obtained.

Having said that, there are obvious shortcomings in these modeling environments. In part, that has inspired analysts to focus on specific integration issues, such as those considered in this paper. Although a specific focus on regulation or load following may have limitations, it can be a very attractive way to isolate specific physical requirements that are imposed by the large-scale use of wind generators.

A number of different studies on different systems are represented in this survey. They all found that wind integration impacts and costs are non-zero and become more significant at higher wind penetrations. These specific numbers represent a range of estimates, based on different system characteristics, different penetration levels of wind, and different study methods. However, a common thread of all methods was the focus on wind's effect on the system, rather than in isolation, and integration costs are relatively small on a per-kWh of wind energy basis. Table 6 collects some of the key attributes and results. The penetration rates are expressed as the rated capacity of the wind plant relative to system peak load.

Although methods and the level of detail varied in these studies, they provide an early indication that ancillary service costs imposed by wind are relatively low for the growth in wind power expected in the next 3-5 years. Future studies and experience gained during that time frame may reveal continued opportunity to integrate wind without large cost impacts as wind penetration increases. 


\section{ACKNOWLEDGEMENTS}

We thank Ed DeMeo, Kevin Porter, Elliot Mainzer, and Charlie Smith for helpful comments on a draft of this paper, and thank Eric Hirst for his important work and vision on integration issues. We also thank Ruth Baranowski for her first-rate editorial support.

\section{REFERENCES}

1. Dragoon K, Milligan M. Assessing wind integration costs with dispatch models: a case study. Windpower 2003. 2003. Austin, TX: AWEA.

2. Kirby B, Hirst E. Customer-specific metrics for the regulation and load following ancillary services. 2000, Oak Ridge National Laboratory: Oak Ridge, TN.

3. NERC, NERC Operating Manual. 2002: Princeton, N.J.

4. Hirst E, Kirby B. Ancillary-service details: dynamic scheduling. 1997, Oak Ridge National Laboratory: Oak Ridge.

5. Hirst E. Integrating wind output with bulk power operations and wholesale electricity markets. Wind Energy 2002; 5 (1): 19-36.

6. Wan Y. Wind power plant monitoring project annual report. 2001, National Renewable Energy Laboratory: Golden, CO.

7. Milligan M. Wind power plants and system operation in the hourly time domain. Windpower 2003. 2003. Austin, TX: AWEA.

8. Milligan M, Factor T. Optimizing the geographic distribution of wind plants in Iowa for maximum economic benefit and reliability. Journal of Wind Engineering 2000. 24(4): 271-290.

9. Brooks EDL, Smith J, Pease J, McGree M. Assessing the impact of wind generation on system operations at Xcel Energy-North and Bonneville Power Administration. Windpower 2002. 2002. Washington, D.C.: American Wind Energy Association.

10. PacifiCorp. Integrated Resource 2003. http://www.pacificorp.com/Navigation/Navigation23807.html. 2003.

11. Hirst E. Integrating wind energy with the BPA power system: preliminary study. http://www.ehirst.com/. September 2002.

12. CAISO. California Independent System Operator Intermittent Tariff, Amendment 42 at http://www.caiso.com/docs/2002/02/01/200202011116576547.html.

13. MISO. Midwest Wind Development Plan. http://www.midwestiso.org/plan inter/index.shtml.

14. Nielson J, Lehr, R. Interior west clean energy plan. Windpower 2003. 2003. Austin, TX: AWEA. 


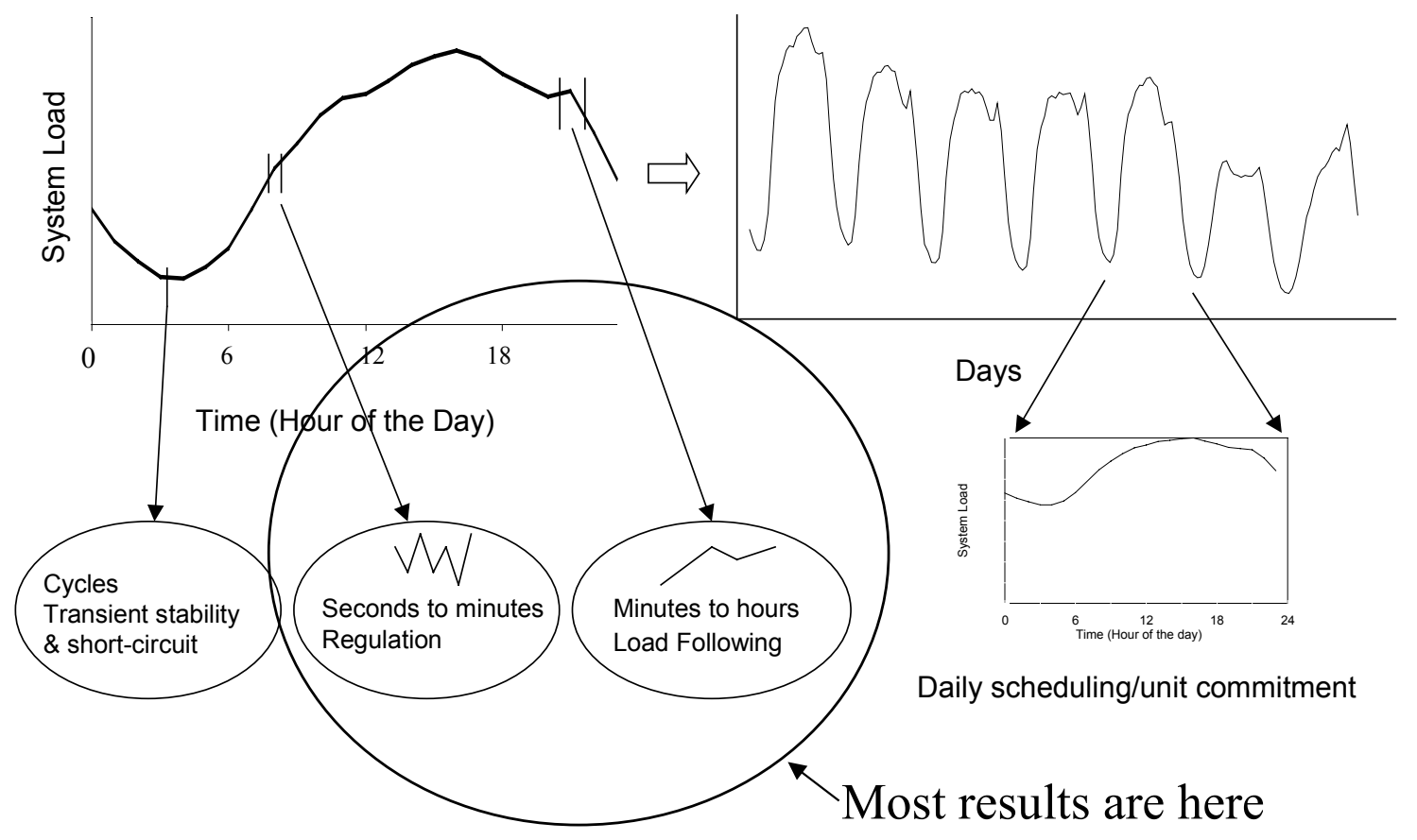

Figure 1. Time scales for utility operations.

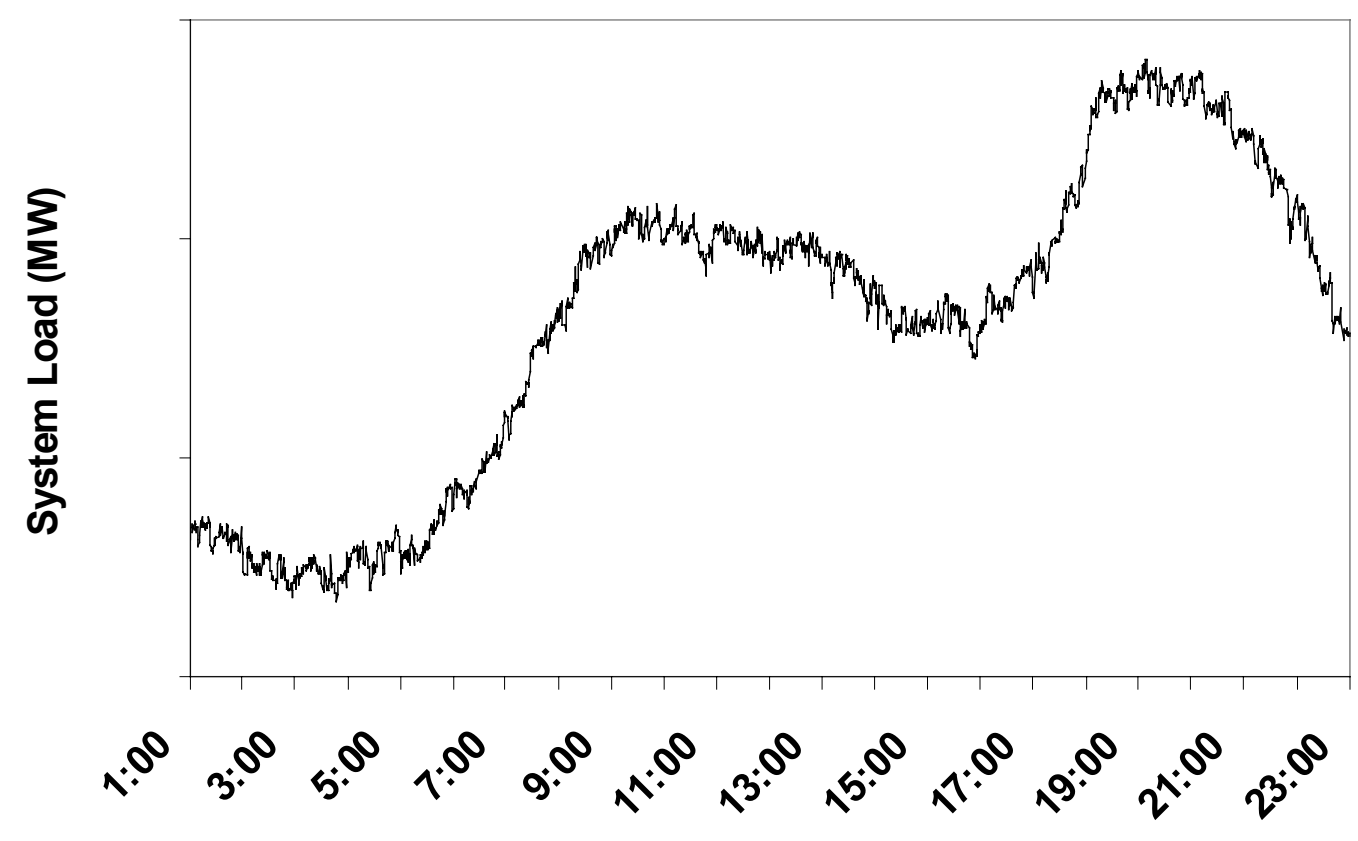

Figure 2. Aggregate load for a typical utility. 


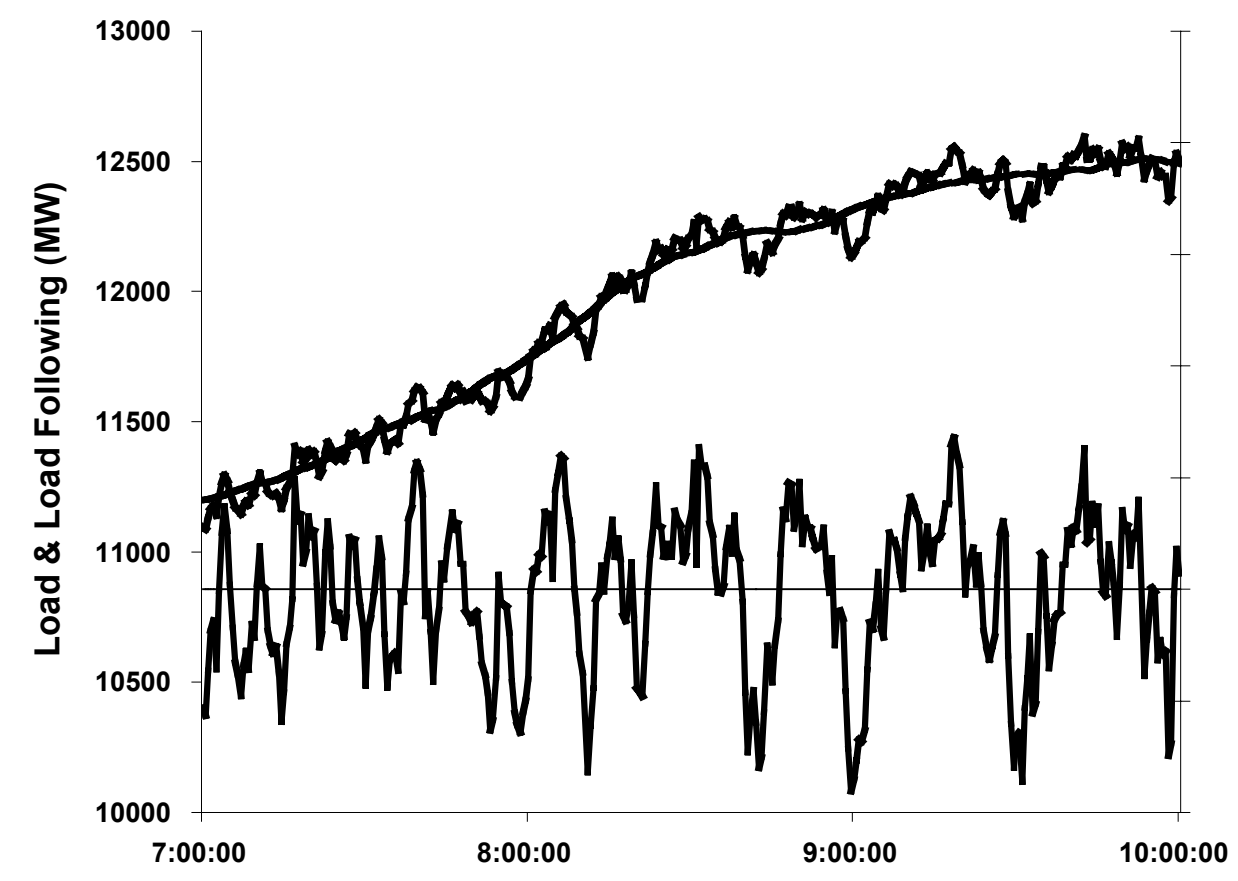

Figure 3. Decomposition of control area loads.

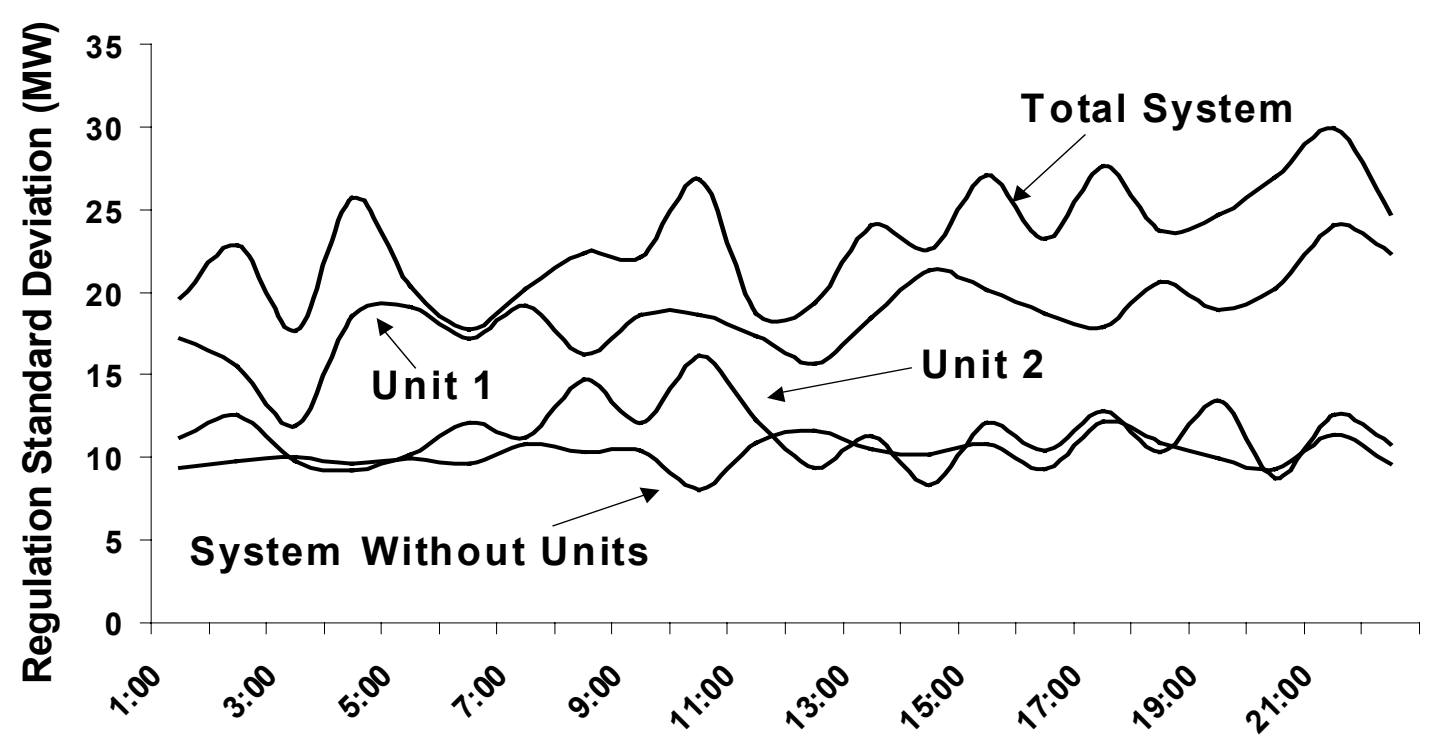

Figure 4. Identifies high-impact individuals; can be applied to regulation and load following. 


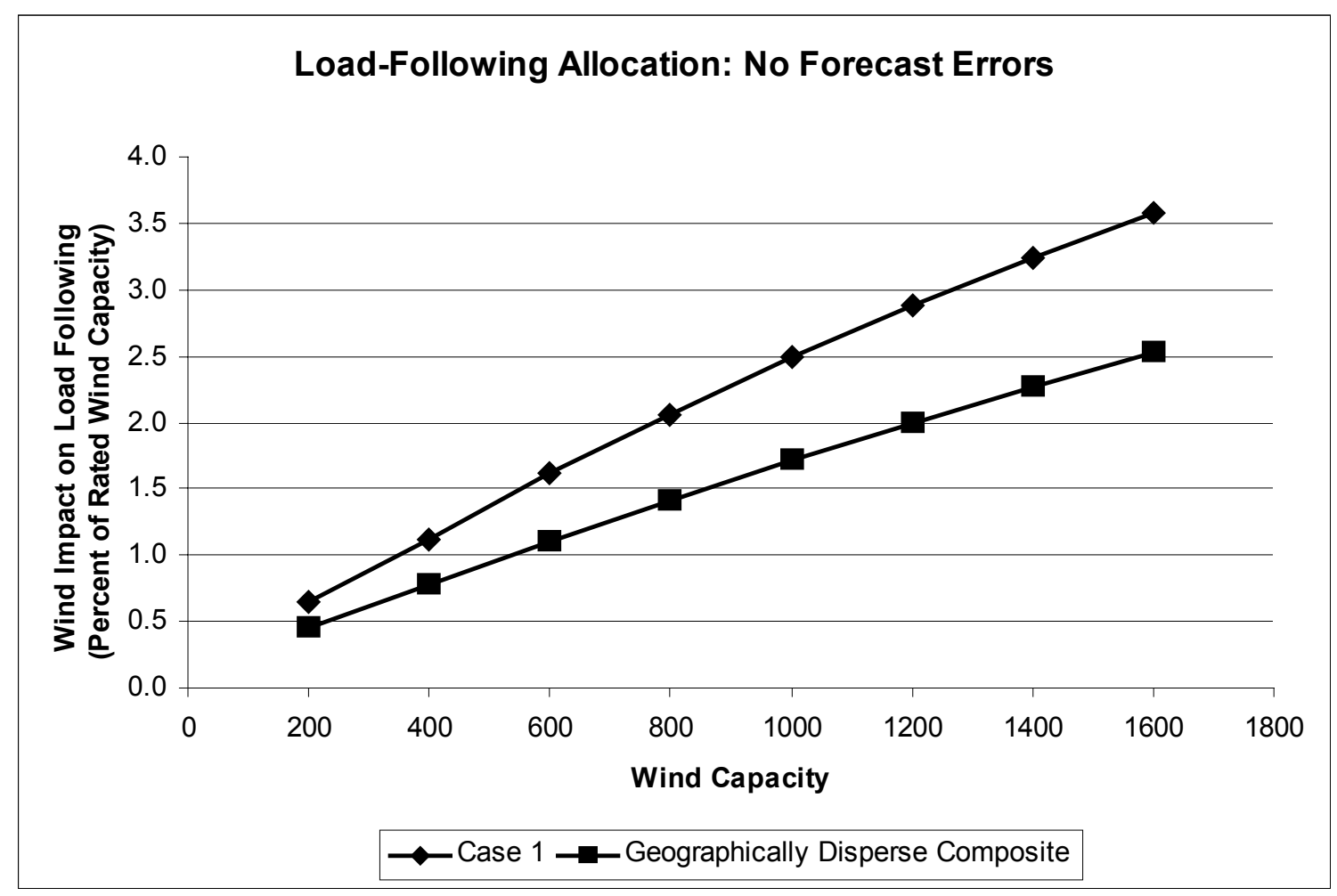

Figure 5. Post hoc load following allocation using ORNL allocation method for Iowa. 


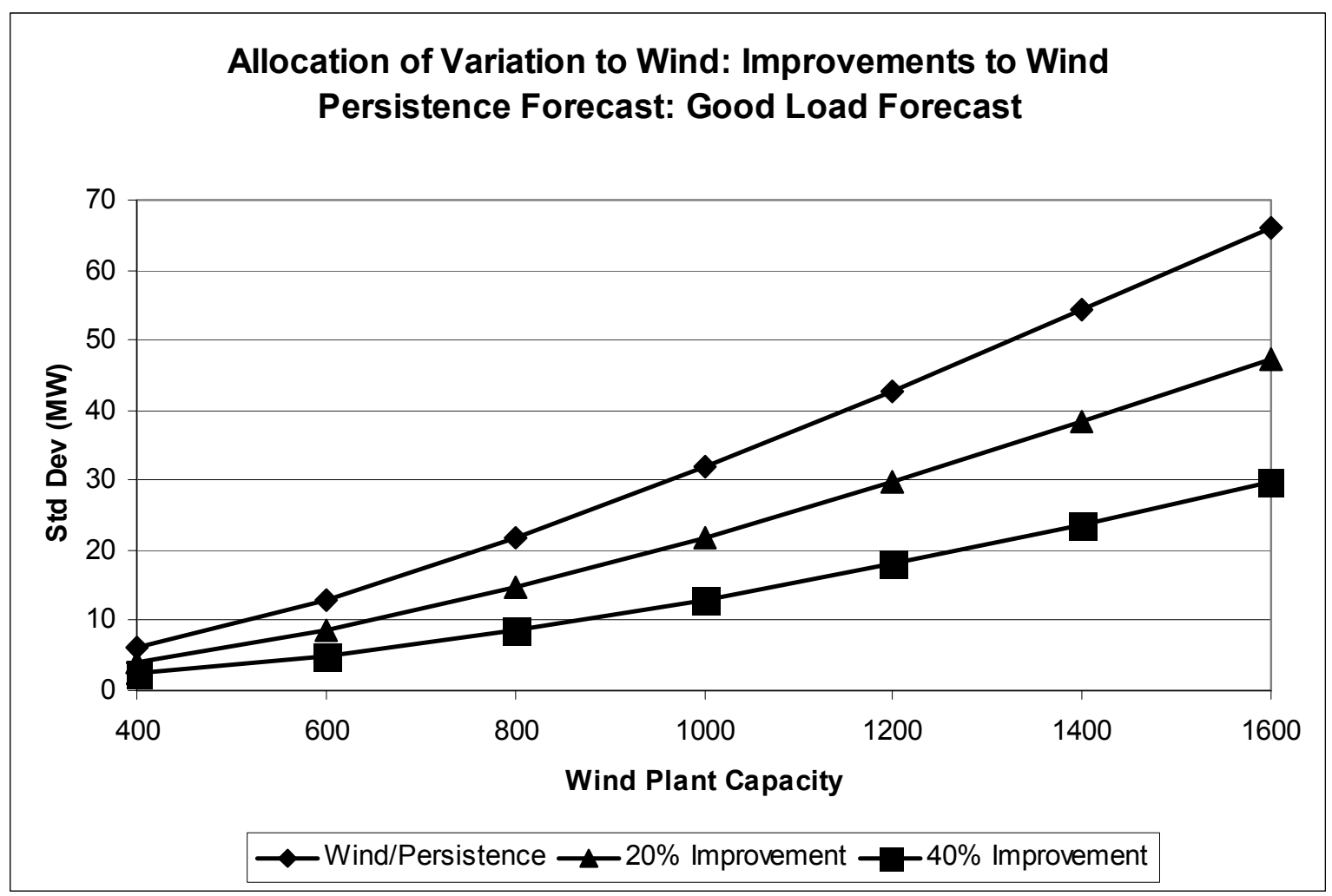

Figure 6. Allocation of imbalance to wind using ORNL allocation method. 


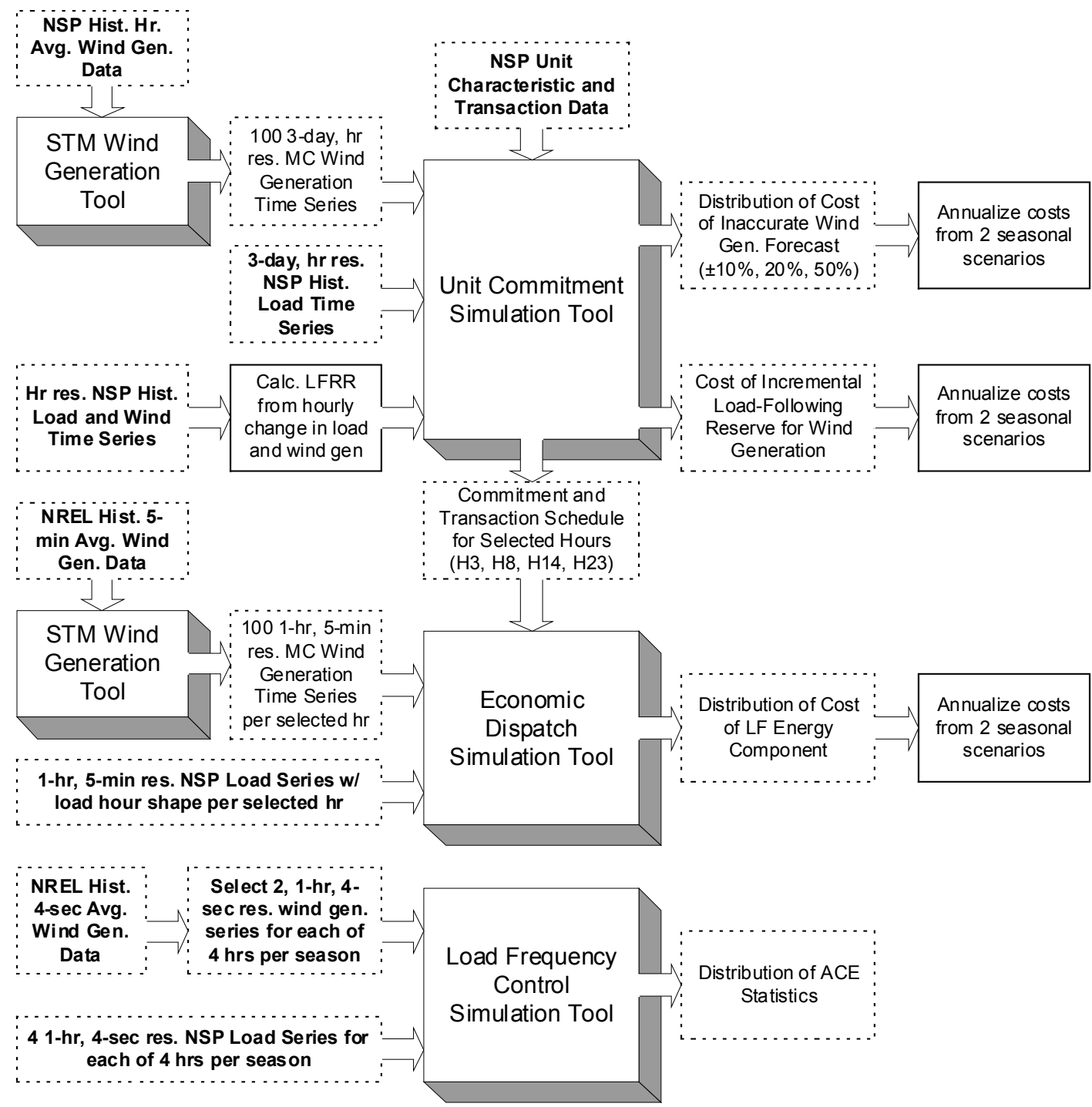

Figure 7. Modeling framework for Electrotek's study of Xcel. 


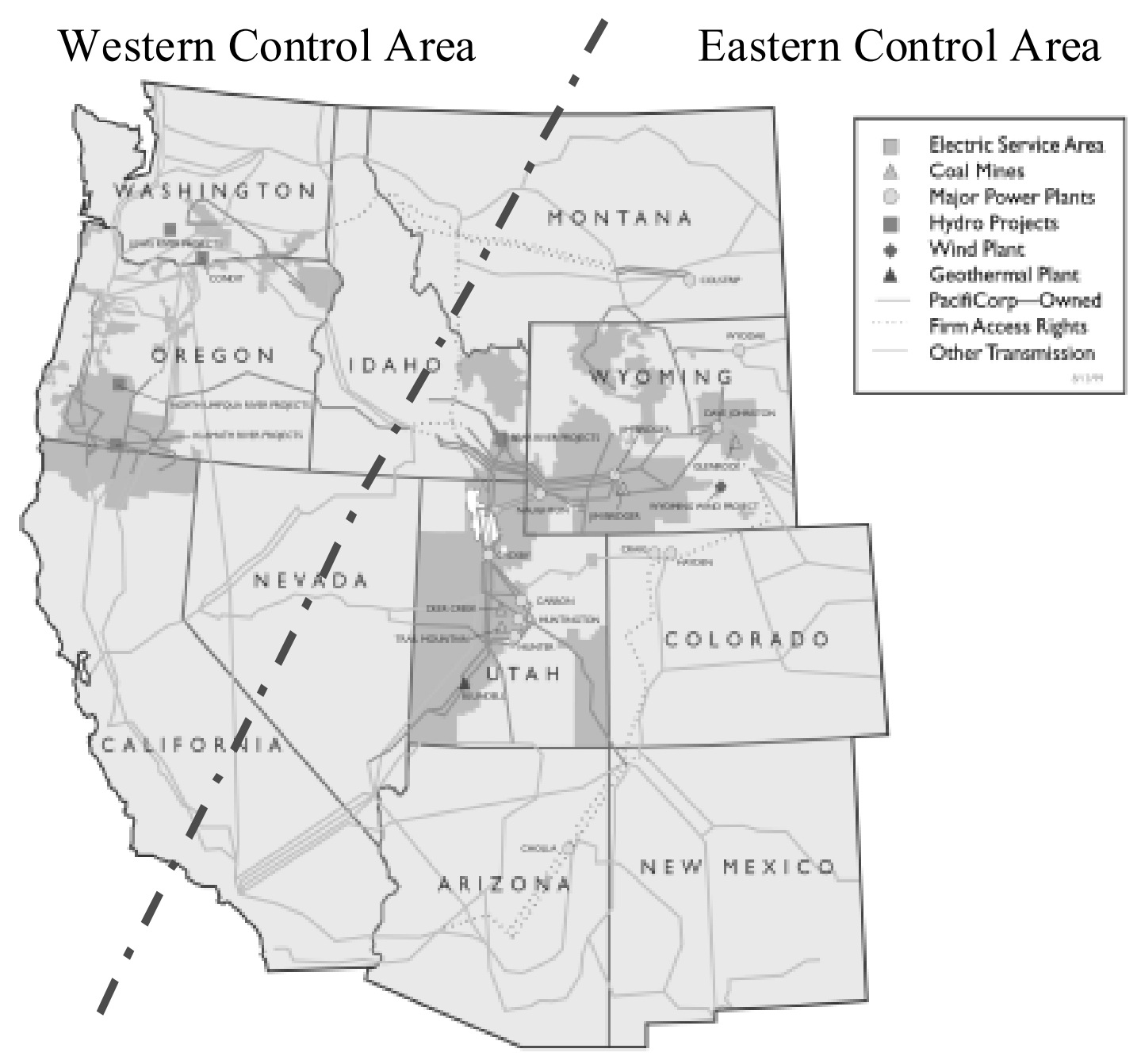

Figure 8. PacifiCorp's power system. 


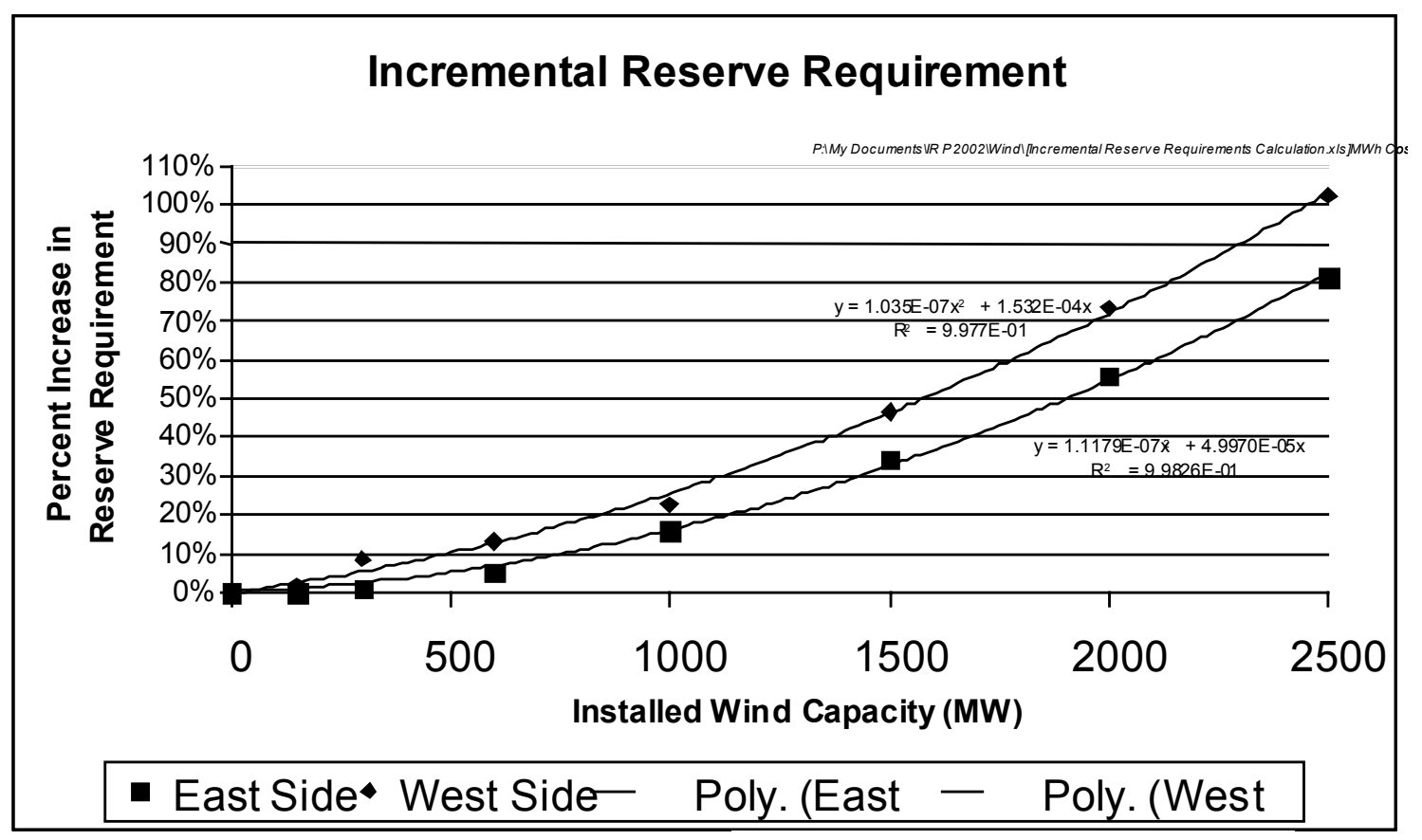

Figure 9. PacifiCorp's incremental reserve requirement results.

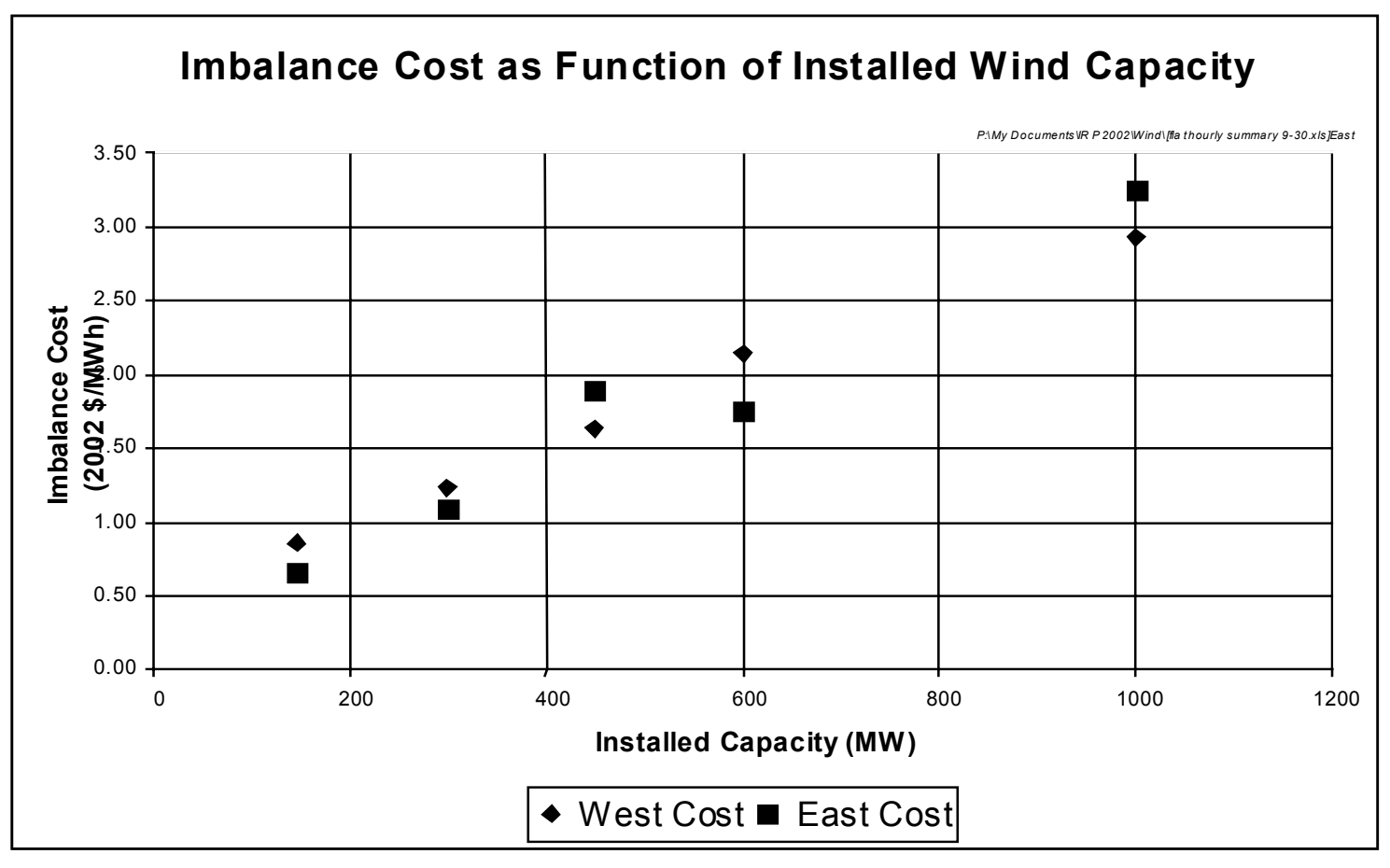

Figure 10. PacifiCorp's imbalance estimates for wind. 


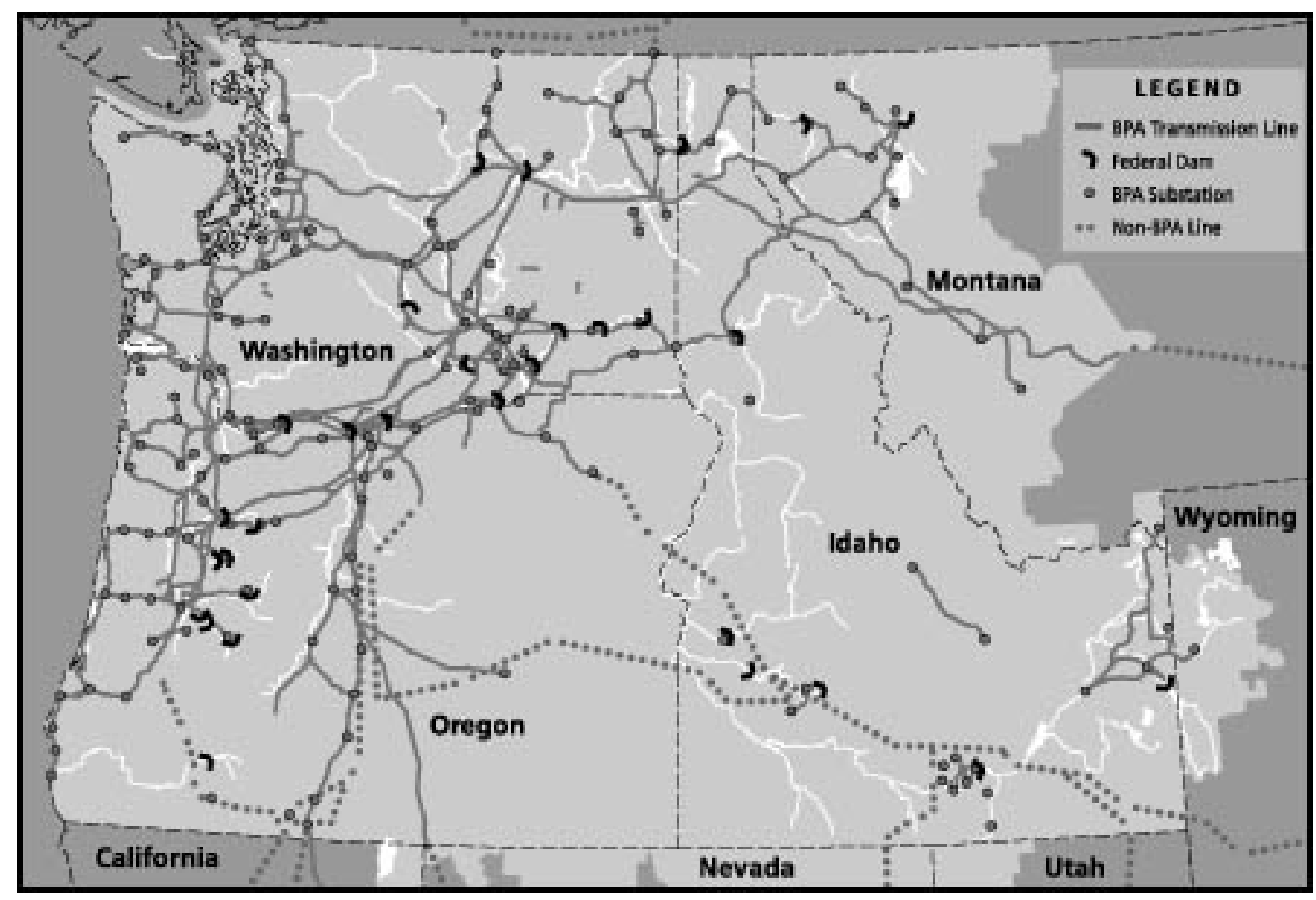

Figure 11. BPA's power system. 
Table 1. Regulation and Load Following Differ

\begin{tabular}{|c|c|c|}
\hline & REGULATION & LOAD FOLLOWING \\
\hline Patterns & Random, uncorrelated & Largely correlated \\
\hline Generator control & AGC & Manual \\
\hline $\begin{array}{c}\text { Maximum swing } \\
(\mathrm{MW})\end{array}$ & Small & $10-20$ times more \\
\hline $\begin{array}{c}\text { Ramp rate } \\
\text { (MW/minute) }\end{array}$ & Many times more & Slow \\
\hline Sign changes & $20-50$ times more & Few \\
\hline
\end{tabular}

Table 2. Hirst Results If Wind Schedules in Hour-Ahead Market

\begin{tabular}{|l|l|l|l|l|}
\hline Month & $\begin{array}{l}\text { Average } \\
\text { MW }\end{array}$ & $\begin{array}{l}\text { Average Price } \\
(\$ / \mathrm{MWh})\end{array}$ & $\begin{array}{l}\text { Imbalance Price } \\
(\$ / \mathrm{MWh})\end{array}$ & $\begin{array}{l}\text { Regulation } \\
\text { Cost } \\
(\$ / \mathrm{MWh})\end{array}$ \\
\hline Aug 2000 & 21.8 & 34.70 & -2.80 & 0.30 \\
\hline Jan 2001 & 37.7 & 33.70 & -0.70 & 0.05 \\
\hline
\end{tabular}

Table 3. Hirst Results If Wind Appears Entirely in Imbalance Market

\begin{tabular}{|l|l|l|}
\hline Month & Average MW & Average Price $(\$ / \mathrm{MWh})$ \\
\hline Aug 2000 & 21.8 & 31.30 \\
\hline Jan 2001 & 37.7 & 32.90 \\
\hline
\end{tabular}


Table 4. Summary of Electrotek's Xcel Results

\begin{tabular}{|l|l|}
\hline & Integration Cost $(\$ / \mathrm{MWh})$ \\
\hline $\begin{array}{l}\text { Forecast errors in day-ahead } \\
\text { scheduling }\end{array}$ & $0.39-1.44$ \\
\hline $\begin{array}{l}\text { Intra-hour Load Following } \\
\text { Energy }\end{array}$ & 0.41 \\
\hline Regulating reserve & No measurable cost impact \\
\hline
\end{tabular}

Table 5. Cost of Integrating 1000 MW of Wind into the BPA System

\begin{tabular}{ll}
\hline Service & $\begin{array}{l}\text { Integration Cost } \\
\text { \$/MWH of Wind Production }\end{array}$ \\
\hline Day-Ahead Forecasting Error & $\$ 1.00-\$ 1.80$ \\
Load Following & $\$ 0.18$ \\
Regulation & $\$ 0.19$ \\
\hline Total & $\$ 1.37-\$ 2.17$ \\
\hline
\end{tabular}




\begin{tabular}{|c|c|c|c|c|c|c|c|}
\hline $\begin{array}{l}\text { Study and } \\
\text { Relative } \\
\text { Wind } \\
\text { Penetration }\end{array}$ & $\begin{array}{l}\text { Analytic } \\
\text { (A) or } \\
\text { Case } \\
\text { Study } \\
\text { (C) }\end{array}$ & Regulation & $\begin{array}{l}\text { Load } \\
\text { Following } \\
\text { (L) or } \\
\text { Imbalance } \\
\text { (I) }\end{array}$ & Reserves & $\begin{array}{l}\text { Unit } \\
\text { Commit- } \\
\text { ment }\end{array}$ & $\begin{array}{l}\text { Allocation } \\
\text { Method } \\
\text { M=Market, } \\
\text { I=Incremental } \\
\text { O=ORNL }\end{array}$ & $\begin{array}{l}\text { Cost } \\
\$ / M W h \\
\text { from } \\
\text { Studied } \\
\text { Time } \\
\text { Scales }\end{array}$ \\
\hline $\begin{array}{l}\text { Hirst PJM } \\
0.06 \%- \\
0.12 \%\end{array}$ & (A) & Y & I & & & $\mathrm{M}$ & $\begin{array}{l}\text { \$.0.05- } \\
\text { \$0.30/MWh } \\
\text { Regulation }\end{array}$ \\
\hline $\begin{array}{l}\text { Milligan IA } \\
\text { up to } 22.5 \%\end{array}$ & (A) & & $\overline{\mathrm{L}, \mathrm{I}}$ & (1) & & $\mathrm{O}$ & (2) \\
\hline $\begin{array}{l}\text { UWIG / } \\
\text { Electrotek } \\
\text { Xcel 3.5\% }\end{array}$ & (C) & $\mathrm{Y}$ & L, I (3) & $\mathrm{Y}$ & $\mathrm{Y}$ & I & $\$ 2.00 / \mathrm{MWh}$ \\
\hline $\begin{array}{l}\text { PacifiCorp } \\
\text { IRP 20\% }\end{array}$ & (C) & & I & $\mathrm{Y}$ & & I & $\$ 5.50 / \mathrm{MWh}$ \\
\hline $\begin{array}{l}\text { Hirst BPA } \\
5.9 \%\end{array}$ & (C) & $\mathrm{Y}$ & $\mathrm{L}, \mathrm{I}$ & & $\mathrm{Y}$ & $\mathrm{O}$ & $\begin{array}{l}\text { \$1.37- } \\
2.17 / \mathrm{MWh}\end{array}$ \\
\hline
\end{tabular}

(1) Used $3 \times$ standard deviation as indirect estimate of reserve requirements.

(2) Cost was not estimated in this study. Allocation of system variation (based on standard deviation) to wind ranged up to $2.5 \%$ of the wind rated capacity for load following and up to $4 \%$ for imbalance, for penetration rates up to $22.5 \%$ based on capacity.

(3) Imbalance energy costs determined from Unit Commitment production cost simulations 


\section{REPORT DOCUMENTATION PAGE}

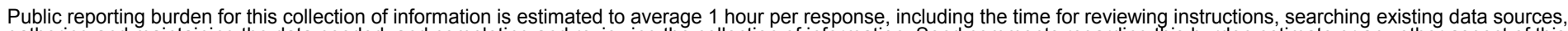

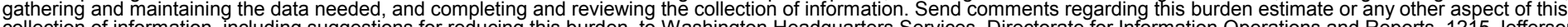
Davis Highway, Suite 1204, Arlington, VA 22202-4302, and to the Office of Management and Budget, Paperwork Reduction Project (0704-0188), Washington, DC 20503.
1. AGENCY USE ONLY (Leave blank)
2. REPORT DATE
3. REPORT TYPE AND DATES COVERED
June 2003
Conference Paper

June 2003

4. TITLE AND SUBTITLE

Grid Impacts of Wind Power: A Summary of Recent Studies in the United States; Preprint 6. $\operatorname{AUTHOR}(\mathrm{S})$

M. Milligan, B. Parsons, B. Zavadil, D. Brooks, B. Kirby, K. Dragoon, and J. Caldwell

7. PERFORMING ORGANIZATION NAME(S) AND ADDRESS(ES)

National Renewable Energy Laboratory

1617 Cole Blvd.

Golden, CO 80401-3393

5. FUNDING NUMBERS

WER3. 3610

9. SPONSORING/MONITORING AGENCY NAME(S) AND ADDRESS(ES)

10. SPONSORING/MONITORING AGENCY REPORT NUMBER

11. SUPPLEMENTARY NOTES

12a. DISTRIBUTION/AVAILABILITY STATEMENT

National Technical Information Service

12b. DISTRIBUTION CODE

U.S. Department of Commerce

5285 Port Royal Road

Springfield, VA 22161

13. ABSTRACT (Maximum 200 words)

Several detailed technical investigations of grid ancillary service impacts of wind power plants in the United States have recently been performed. These studies were applied to Xcel Energy (in Minnesota) and PacifiCorp and the Bonneville Power Administration (both in the northwestern United States). Although the approaches vary, three utility time frames appear to be most at issue: regulation, load following, and unit commitment. This paper describes and compares the analytic frameworks from recent analysis and discusses the implications and cost estimates of wind integration. The findings of these studies indicate that relatively large-scale wind generation will have an impact on power system operation and costs, but these impacts and costs are relatively low at penetration rates that are expected over the next several years.

14. SUBJECT TERMS
wind energy; wind power plants; utility grid; Xcel Energy; PacifiCorp; Bonneville Power Administration

17. SECURITY CLASSIFICATION OF REPORT Unclassified

NSN 7540-01-280-5500
19. SECURITY CLASSIFICATION OF ABSTRACT Unclassified
15. NUMBER OF PAGES

16. PRICE CODE

20. LIMITATION OF ABSTRACT

UL 